\title{
Heart Rates and Blood Lactate Response in Thoroughbred Horses during a Race
}

\author{
Kazutaka MUKAI ${ }^{1}$, Toshiyuki TAKAHASHI ${ }^{1}$, Daisuke ETO $^{1}$, Hajime $^{\text {OHMURA }}{ }^{1}$, \\ Hirokazu TSUBONE ${ }^{2}$ and Atsushi HIRAGA ${ }^{1}$ \\ ${ }^{1}$ Equine Research Institute, Japan Racing Association, 321-4 Tokami-cho, Utsunomiya, Tochigi 320-0856, \\ ${ }^{2}$ Department of Comparative Pathophysiology, Graduate School of Agricultural and Life Sciences, The \\ University of Tokyo, 1-1-1 Yayoi, Bunkyo-ku, Tokyo 113-8657, Japan
}

We measured the heart rate before, during and after a 1200-m race, and blood lactate concentration at 10 min after a race in 23 Thoroughbred horses. The heart rate increased when horses were walking through the underground passage and after the jockeys mounted them in the paddock, even though there was no increase in exercise intensity. During the canter from the exit of the underground passage to the starting stalls, the heart rate increased to a peak value of $194.0 \pm 2.0$ (mean $\pm S E$ ) beat $/ \mathrm{min}$, which was equivalent to $91.1 \pm 0.8 \%$ of the maximal racing heart rate. In the starting stalls immediately before the start of the race, the heart rate was $171.4 \pm 5.3$ beat/min. The peak value of the heart rate $\left(H R_{\text {peak }}\right)$ during the race was $213.6 \pm 1.7 \mathrm{beat} / \mathrm{min}$, and the time taken to reach $95 \%$ of $H R_{\text {peak }}$ was $12.4 \pm 1.8 \mathrm{sec}$. The blood lactate concentration after the race was $22.5 \pm 0.6 \mathrm{mmol} / \mathrm{l}$. The mean speed of the horses was $15.9 \pm 0.0 \mathrm{~m} / \mathrm{s}$, which was similar to those of 3-year-olds in maiden races. These data could be useful for planning training strategies for Thoroughbred horses.

Key words: exercise, heart rate, horse, lactate, race
J. Equine Sci.

Vol. 18, No. 4

pp. 153-160, 2007
It is important to understand the physiological condition of Thoroughbred horses during races and to construct training protocols to adapt them to these severe race events. However, there have been few studies of them [19] due to many limitations in measuring exercise physiological variables in Thoroughbreds during a race. More than $70 \%$ of the energy is supplied through the aerobic pathway during intense exercise lasting for 1 to $3 \mathrm{~min}$ in horses [6, 7]. In humans, maximal oxygen uptake $\left(\dot{\mathrm{V}}_{2 \max }\right)$ has been most reliable in evaluating aerobic capacity and is considered the "gold standard" by which prolonged exercise can be judged. Many publications have shown that there is a correlation between athletic performance and $\dot{\mathrm{V}}_{2 \max }$ in humans $[2,4,20]$. Although there are many benefits in measuring $\dot{\mathrm{V}}_{2 \max }$, application of this measurement to racehorses has been difficult, because it requires the racehorses to run on a high-speed

This article was accepted September 28, 2007

*Corresponding author. e-mail: mukai@center.equinst.go.jp treadmill in the laboratory, to acclimate to the treadmill, and to run until exhaustion. Trainers rarely accept these experimental conditions. In contrast, heart rate is well correlated with oxygen consumption during exercise [5], can easily be measured, and has been conventionally used as an index to evaluate cardiorespiratory functions in horses under field conditions [18, 25, 28]. Many researchers indicate that psychological conditions can influence athletic performance, putting forward the inverted-Uhypothesis as a useful working model of the relationship between arousal and performance [13, 17].

On the other hand, short-term supramaximal exercise results in intramuscular production of lactate in racehorses [21,39]. The rate of lactate accumulation in skeletal muscles and its release into blood is exponentially related to an increase of $\dot{\mathrm{VO}}_{2}$ accompanied with exercise intensity [15]. On the basis of this relationship, the lactate concentration in blood or plasma may provide valuable information about the working muscles and the rest of the body [12]. In 
particular, data obtained after racing indicate the animal's response under conditions of actual competition and also of pre-race excitement. In addition, these data lead to an understanding of the demands of racing and aid in the planning of training schedules.

In this study, we have investigated heart rate throughout a race and the post-race blood lactate concentration in Thoroughbred horses to evaluate exercise intensity and psychological changes during the race.

\section{Materials and Methods}

Horses

Twenty-three Thoroughbred horses $(8$ males, 1 gelding, 14 female; $4.0 \pm 0.2 \mathrm{yr}, 451.9 \pm 6.6 \mathrm{~kg}$ ) in a racing condition were used in this study. Horses were trained for their race 6 days/week on a dirt track at The Horse Racing School of the Japan Racing Association (JRA). All horses were transported by horse vans on the day of the race, and were found to be clinically healthy with no lameness at the veterinary inspection before the race. Horses were weighed approximately 20 min after the race.

Race

The three simulated races of $1,200 \mathrm{~m}$ on a dirt surface, with eight, ten and five horses, respectively, were held at the Nakayama Racecourse of the JRA. The Nakayama Racecourse is one of the biggest racecourses in Japan and holds big races such as the international Nakayama Grand Jump, the Arima Kinen (Grand Prix race), the Satsuki Sho (Japanese 2000 Guineas) and Sprinters Stakes. The dirt course of the Nakayama Racecourse is $1,493 \mathrm{~m}$ and its home stretch is $308 \mathrm{~m}$, and the racing direction is clockwise. Each horse was saddled up with a heart rate monitor (S810, Polar Electro Oy, Kempele, Finland) approximately $50 \mathrm{~min}$ before the start and was walked for $15 \mathrm{~min}$ around the stable. Then, the horses then passed through an underground passage and arrived at the paddock 30 min before the race. After 15-min of walking around the paddock, the horses were mounted by the jockeys and left for the course, passing through the underground passage again. On the course, they cantered for several hundred meters as a warm-up exercise before gathering to the starting stalls. Odd-

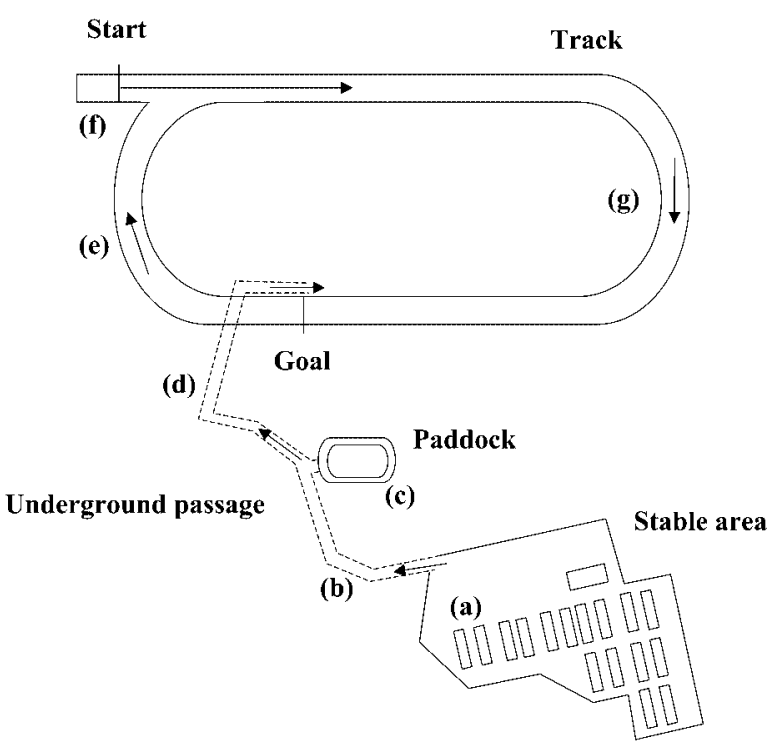

Fig. 1. The route of horses in the Nakayama Racecourse of JRA. (a) Walking around the stable. (b) Walking through the underground passage. (c) Walking in the paddock. (d) Walking through the underground passage with jockey mounted. (e) Galloping to the starting stalls. (f) In the starting stalls. (g) During the race.

numbered horses were loaded into the stalls first, followed by even-numbered horses (Fig. 1). After each race, each horse was unsaddled and walked for $10 \mathrm{~min}$. Then blood samples from the jugular vein were collected using 18 gauge needles and vacuum-sealed tubes containing sodium fluoride and EDTA, and were retained on ice until analysis. Blood lactate concentrations were measured with an automatic lactate analyzer (YSI-2300 STAT Plus, Yellow Springs Instruments, Yellow Springs, USA). The race time was measured with an automatic timing device that utilizes infrared ray beams. The race was videotaped and the horses' speed was also measured by checking the videotape.

\section{Heart rate}

During the race, a Polar HR Monitor S810 was used to measure the average heart rate over 5 -sec intervals. One of electrodes of the heart rate monitor was attached to the sponge set under the saddle, whereas the other electrode, the transmitter and the receiver of the heart rate monitor were attached to the elastic girth. 


\section{Statistical analysis}

Data are means $\pm \mathrm{SE}$ of horses across the three races. Data were analyzed for differences between the heart rates at various stages using repeated measures ANOVA, and pairwise comparisons were made using Tukey's test. Statistical significance was defined as $\mathrm{P}<0.05$. Statistical analyses were made using JMP v. 5.0.1a software.

\section{Results}

\section{Heart rate (Fig. 2, Table 1. b)}

The heart rate of 2 horses was not recorded from the onset of the experiment and the heart rate of another 2 horses was not recorded after the horses gathered at the starting point.

When horses were walking around the stable, the heart rate was $73.3 \pm 2.9 \mathrm{beat} / \mathrm{min}$. After entering the underground passage, the heart rate of horses increased significantly to $88.0 \pm 4.2 \mathrm{beat} / \mathrm{min}$. A heart rate of $71.1 \pm 2.8 \mathrm{beat} / \mathrm{min}$ was recorded when the horses were being led by grooms around the paddock, but the heart rate increased to $97.3 \pm 4.6$ beat $/ \mathrm{min}$ after the jockeys mounted the horses. When the horses were walking to the course with the jockeys riding in the underground passage, the heart rate was $114.3 \pm 5.4$ beat/min, which was significantly higher than in the paddock with the jockeys mounted. During the canter from the exit of the underground passage to the starting stalls as a warm-up, the recorded heart rate increased to a peak value of $194.0 \pm 2.0 \mathrm{beat} / \mathrm{min}$. After gathering around the starting stalls, the horses were walking with a heart rate of $97.7 \pm 3.5$ beat $/ \mathrm{min}$. In the

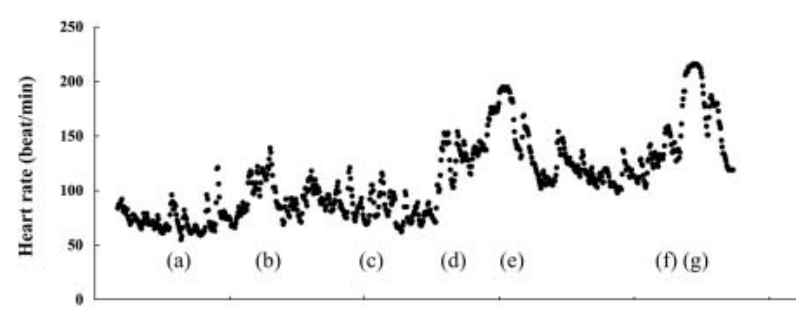

Fig. 2. Typical pattern of heart rate from saddling-up to unsaddling. (a) Walking around the stable. (b) Walking through the underground passage. (c) Walking in the paddock. (d) Walking through the underground passage with jockey mounted. (e) Galloping to the starting stalls. (f) In the starting stalls. (g) During the race.

Table 1. Thoroughbred horse characteristics

(a)

\begin{tabular}{llr}
\hline & Units & Values \\
\hline Run time & $\mathrm{sec}$ & $75.6 \pm 0.2$ \\
Running speed & $\mathrm{m} / \mathrm{s}$ & $15.9 \pm 0.0$ \\
Body weight & $\mathrm{kg}$ & $451.9 \pm 6.6$ \\
Blood lactate concentration & $\mathrm{mmol} / \mathrm{l}$ & $22.5 \pm 0.6$ \\
$t_{95 \%}$ & $\mathrm{sec}$ & $12.4 \pm 1.8$ \\
\hline (b) & & \\
\hline Heart rate & Units & Values \\
\hline Around the stable & beat/min & $73.3 \pm 2.9^{\mathrm{a}}$ \\
Underground passage & beat/min & $88.0 \pm 4.2^{\mathrm{b}}$ \\
Paddock & beat/min & $71.1 \pm 2.8^{\mathrm{a}}$ \\
Paddock with jockeys & beat/min & $97.3 \pm 4.6^{\mathrm{b}}$ \\
Underground passage with jockeys & beat/min & $114.3 \pm 5.4^{\mathrm{c}}$ \\
Around the starting stalls & beat/min & $97.7 \pm 3.5^{\mathrm{b}}$ \\
In the starting stalls & beat/min & $171.4 \pm 5.3^{\mathrm{d}}$ \\
Galloping to the starting stalls (peak values) & beat/min & $194.0 \pm 2.0$ \\
During a race (peak values) & beat/min & $213.6 \pm 1.7^{-}$ \\
\hline
\end{tabular}

Shown are (a) run time, running speed, body weight, blood lactate concentration 10 min after the race and the mean time taken to reach $95 \%$ of peak heart rate $\left(t_{95}\right)$, and (b) the heart rate at various stages from saddling-up to unsaddling during a race. Values are means \pm SE. Different letter superscripts indicate significant differences between values $(\mathrm{P}<0.05)$. 


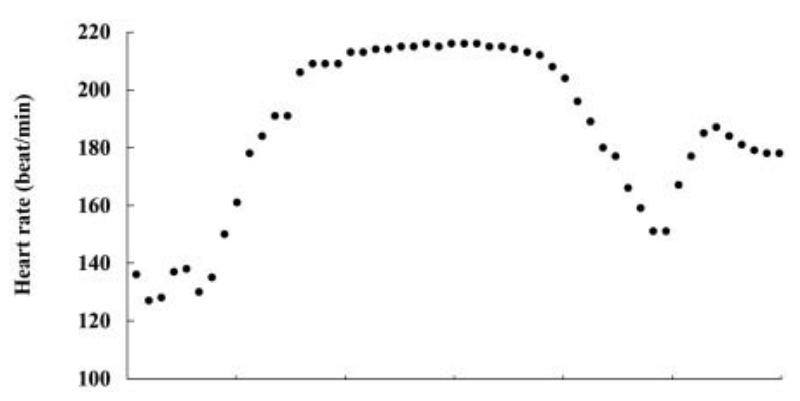

Fig. 3a

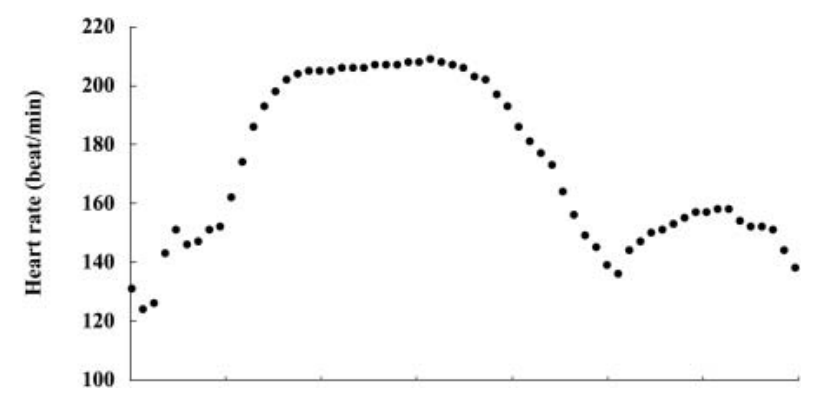

Fig. 3b

starting stalls immediately before the start of the race, the heart rate increased to $171.4 \pm 5.3$ beat $/ \mathrm{min}$. The peak value of the heart rate $\left(\mathrm{HR}_{\text {peak }}\right)$ during the race was $213.6 \pm 1.7 \mathrm{beat} / \mathrm{min}$ and the time taken to reach $95 \%$ of $\mathrm{HR}_{\text {peak }}$ was $12.4 \pm 1.8 \mathrm{sec}$.

Three typical patterns of variation in the heart rate measured during the race are shown in Fig. 3a-3c. In Fig. 3a, once the heart rate had risen to the peak value, it remained stable throughout the race. In Fig. 3b, the heart rate was constant in the early stages and gradually increased in the latter periods. In Fig. 3c, after the heart rate reached its peak, it decreased gradually throughout the rest of the race.

\section{Blood lactate concentration}

The mean blood lactate concentration of the 23 horses $10 \mathrm{~min}$ after the race was $22.5 \pm 0.6 \mathrm{mmol} / \mathrm{l}$ (Table 1. a).

\section{Running speed}

The mean race time and speed of all of the horses in the three 1,200-m races were 75.6 $\pm 0.2 \mathrm{sec}$ and $15.9 \pm$ $0.0 \mathrm{~m} / \mathrm{sec}$, respectively (Table $1 . \mathrm{a}$ ).

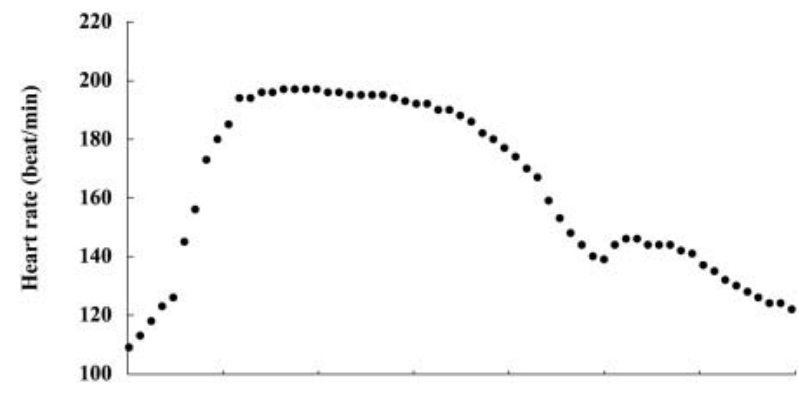

Fig. 3c

Fig. 3. Three typical patterns of variation in heart rate during a race. (a) The heart rate remained stable throughout the race. (b) The heart rate was initially unchanged and increased in the last phase of the race. (c) The heart rate decreased gradually during the race.

\section{Discussion}

The mean run time of all horses in this study was similar to that of 3-year-olds in maiden races at the Nakayama Racecourse, and the mean speed of the horses was faster than that reported by Krzywanek et al. $(15.4 \mathrm{~m} / \mathrm{sec})[19]$. These results indicate that the horses used in this study were well-trained and that the races were of moderate quality to represent standard races.

The mean heart rate in the starting stalls just before the start of the race was $171.4 \pm 5.3$ beat $/ \mathrm{min}$. This increase in the heart rate indicated how excited the racehorses were before the start and may be the preparation for the following intensive bout of sprint exercise. The heart rate at the starting stalls in our study was higher than that reported by Krzywanek et al. [19] and this may result in an acceleration in the kinetics of oxygen consumption during subsequent intense exercise, given that a shorter time will be needed for the heart rate to reach maximal frequency as compared with the results of Krzywanek's study. Furthermore, Hada et al. [14] demonstrated that psychological stress before intense exercise reduced blood lactate accumulation and enhanced running performance in horses, suggesting that there is 
increased contribution of aerobic metabolism to total energy production due to the increase in heart rate and haematocrit during intense exercise. On the other hand, it is also possible that over-excitement of horses may cause negative effects, such as getting off to a slow start or causing overrunning during the race. Krzywanek et al. also stated that the heart rate in the starting stall was recorded at a period of relative calm and this pre-start period was very variable depending on physical exertion and excitement. This variability may contribute to the difference between the results of Krzywanek and our study. In fact, in our study some horses tended to be excited just after entering the starting stalls, but gradually calmed down and showed a decrease in heart rate while waiting for the other horses to enter the stalls.

The peak heart rate during a warm-up exercise performed after entering the track was $194.0 \pm 2.0$ beat $/ \mathrm{min}$, which was equivalent to $91.1 \pm 0.8 \%$ of the maximal racing rate $(213.6 \pm 1.7$ beat $/ \mathrm{min})$. Some studies have referred to the effects of warm-up exercise in horses. However, the intensities of the warm-up exercise in those studies tended to be relatively low, that is, $30-50 \% \dot{\mathrm{VO}}_{2 \max }$, and the durations of warm-up protocols were mostly over $5 \mathrm{~min}[11,22,23,41]$. From these results, the further research might be needed to investigate the effect of warm-up exercise under the conditions experienced by Thoroughbred races. Although the warm-up intensity in this study seems to be relatively high, both the warm-up duration $(<1 \mathrm{~min})$ and the warm-up distance $(<600 \mathrm{~m})$ were short, and the recovery time between the warm-up and the race was long (approximately $15 \mathrm{~min}$ ). According to our unpublished data, the blood lactate concentration after the warm-up exercise in the present study is estimated to decrease to less than $2 \mathrm{mmol} / \mathrm{l}$ during the recovery time of $15 \mathrm{~min}$; thus, this warm-up exercise is expected to have little effect on fatigue.

After jockeys mounted the horses in the paddock, the walking heart rate increased, and this effect was also reported by Krzywanek et al [19]. A load of about $50 \mathrm{~kg}$ is physically applied when a jockey mounts a horse, and it is expected that the heart rate during a walk may increase owing to this load. However, Sloet van Oldruitenborgh-Oosterbaan et al. [36] undertook a study to investigate the influence of additional loading on heart rate in horses exercising submaximally on a treadmill and found that the heart rate during walking $(1.7 \mathrm{~m} / \mathrm{sec})$, trotting $(4.0 \mathrm{~m} / \mathrm{sec})$ and cantering $(7.0$ $\mathrm{m} / \mathrm{sec}$ ) did not differ significantly under three conditions: unloaded, mounted by a rider of $90 \mathrm{~kg}$ and loaded with $90 \mathrm{~kg}$ of lead [36]. Thus, the increase in heart rate measured after the jockeys mounted may not be due simply to a physical load, but may be related to other factors, such as psychological factors.

In horses, the rate at which $\dot{\mathrm{VO}}_{2}$ can increase with the onset of intense exercise is remarkable. Rose et al. [34] demonstrated in horses exercising at 120 percent of $\dot{\mathrm{VO}}_{2 \max }$ that the mean time taken to reach 50 and $95 \%$ of $\dot{\mathrm{VO}}_{2 \max }$ was 9.8 and $60 \mathrm{sec}$, respectively, and that $\dot{\mathrm{VO}}_{2}$ reached a steady state by $75 \mathrm{sec}$. Even during a run at $125 \% \dot{\mathrm{VO}_{2 \max }}$ that lasted for only a minute, 70 percent of the energy demand was supplied from aerobic pathway [7]. This intensity is equivalent to a sprint race of $1,000 \mathrm{~m}$. In humans, by contrast, anaerobic capacity assumes a more substantial role, contributing approximately $50 \%$ of the energy supply in supramaximal exercise of 1 min duration [24]. Our study and Krzywanek's study showed that the heart rate may increase more rapidly to $95 \%$ of its peak value than to $\dot{\mathrm{V}} \mathrm{O}_{2}$, which required $60 \mathrm{sec}$ to reach $95 \%$ of $\dot{\mathrm{V}}_{2 \text { max }}$

Heart rate is highly correlated with work effort in running horses; however, the heart rate during exercise levels off towards a maximal heart rate level at very high intensities of exercise. Therefore, this should be considered when evaluating fitness based on the heart rate/work relationship. As the heart rate of many horses in the present study remained stable at the peak value during the race (Fig. 3a), the running speed of these horses may basically be stable throughout the race. There were also horses whose heart rate during the race gradually deceased (Fig. 3c); this may be explained by a few possibilities, including a decrease in running speed or an overshoot of heart rate. The heart rate rises rapidly at the outset of exercise, reaching a maximum in approximately 30 to $45 \mathrm{sec}$, and then often drops before reaching a plateau during steadystate work [21]. This overshoot of heart rate will vary depending on the level of exercise intensity, the temperament of the horse and the warm-up period [26, 27]. In several horses, the heart rate continued to increase gradually during the race in this study (Fig.3b). The relative heart rate (as a percentage of the maximal heart rate) is highly correlated with relative oxygen consumption in horses during treadmill exercise [10]. It is known that during heavy exercise that causes significant lactic acidosis, oxygen uptake does not achieve an early steady state but continues to rise for several minutes until exercise is terminated or 
exhaustion occurs $[1,30,35]$. The physiological mechanisms for this slow component of $\dot{\mathrm{VO}}_{2}$ are not clearly understood. Several factors have been suggested to explain this component, including a change in blood lactate concentration, an increase in muscle temperature, an additional cost of ventilation caused by fatigue [3, 30]. Recently, it has been suggested that the percentage of type II fibers in the working muscles seems to be highly related to the amplitude of the slowly increasing $\mathrm{VO}_{2}$ component [29]. The percentage of type II fibers in the middle gluteal muscle in Thoroughbred horses is reported to exceed $80 \%$ [8, 9, 37, 38, 40, 42, 43]. A high ratio of type II fibers in Thoroughbred horses is consistent with the hypothesis that the $\dot{\mathrm{VO}}_{2}$ slow component during high-intensity exercise is related to the energetics of contraction of type II fibers [29].

The high blood lactate concentration $(22.5 \pm 0.6$ $\mathrm{mmol} / \mathrm{l}$ ) in this study strongly reflects a dependence on anaerobic metabolic pathways during the race. Lactate is produced in the working muscle by the glycolytic pathway during all types of exercise, and the blood lactate concentration increases because of diffusion and/or active transport of lactate via monocarboxylate transporters from the working skeletal muscle. High lactate concentrations do not occur, however, until higher intensities of exercise are reached. Although our lactate concentration seems to be lower than values measured with plasma in other studies [16, 39], it is considered to be of a magnitude similar to those previously reported because lactate concentrations in plasma are about 30\% higher than those in blood [3133]. It is known that horses with a high anaerobic capacity have highest peak plasma lactate concentrations after a maximal exercise test [7]; therefore, strengthening the glycolytic capacity and the ability to tolerate conditions of high lactate, and removing lactate from the muscle by transport through the blood may be important in racing.

In conclusion, we have demonstrated that 1) the heart rate of horses increases in the underground passage, after jockeys mount the horses in the paddock, and in the starting stalls just before the start of the race; 2 ) the intensity of warm-up exercise prior to a race is relatively high; 3 ) the exercise intensity during a race is intense enough to utilize both aerobic and anaerobic energy resources; 4) the time required to reach $95 \%$ of $\mathrm{HR}_{\text {peak }}$ is shorter than that taken to reach $95 \%$ of $\dot{\mathrm{VO}}_{2 \max }$ [34]. Although further studies are required in larger populations of horses, the data from this study could help both trainers and veterinarians to manage training strategies for Thoroughbred horses.

\section{Acknowledgments}

The authors wish to thank the staff of the Horse Racing School of the Japan Racing Association for expert technical assistance and husbandry throughout the study.

\section{References}

1. Barstow, T.J., and Mole, P.A. 1991. Linear and nonlinear characteristics of oxygen uptake kinetics during heavy exercise. J. Appl. Physiol. 71: 2099-2106.

2. Brandon, L.J., and Boileau, R.A. 1992. Influence of metabolic, mechanical and physique variables on middle distance running. J. Sports Med. Phys. Fitness 32: 1-9.

3. Casaburi, R., Storer, T.W., Ben-Dov, I., and Wasserman, K. 1987. Effect of endurance training on possible determinants of $\dot{\mathrm{VO}}_{2}$ during heavy exercise. J. Appl. Physiol. 62: 199-207.

4. Davies, C.T. 1980. Effect of air resistance on the metabolic cost and performance of cycling. Eur. J. Appl. Physiol. Occup. Physiol. 45: 245-254.

5. Eaton, M.D., Evans, D.L., Hodgson, D.R., and Rose, R.J. 1995. Effect of treadmill incline and speed on metabolic rate during exercise in thoroughbred horses. J. Appl. Physiol. 79: 951-957.

6. Eaton, M.D., Evans, D.L., Hodgson, D.R., and Rose, R.J. 1995. Maximal accumulated oxygen deficit in thoroughbred horses. J. Appl. Physiol. 78: 1564-1568.

7. Eaton, M.D., Rose, R.J., and Evans, D.L. 1992. The assessment of anaerobic capacity of thoroughbred horses using maximal accumulated oxygen deficit. Aust. Equine Vet. J. 10: 86.

8. Eto, D., Yamano, S., Kasashima, Y., Sugiura, T., Nasu, T., Tokuriki, M., and Miyata, H. 2003. Effect of controlled exercise on middle gluteal muscle fibre composition in Thoroughbred foals. Equine Vet. J. 35: 676-680.

9. Eto, D., Yamano, S., Mukai, K., Sugiura, T., Nasu, T., Tokuriki, M., and Miyata, H. 2004. Effect of high intensity training on anaerobic capacity of middle gluteal muscle in Thoroughbred horses. Res. Vet. Sci. 76: 139-144. 
10. Evans, D.L., and Rose, R.J. 1987. Maximum oxygen uptake in racehorses: changes with training state and prediction from submaximal cardiorespiratory measurements. pp. 52-67. In: Equine Exercise Physiology 2, (Gillespie, J.R., and Robinson, N.E. eds.), ICEEP Publications, Davis, CA.

11. Geor, R.J., McCutcheon, L.J., and Hinchcliff, K.W. 2000. Effects of warm-up intensity on kinetics of oxygen consumption and carbon dioxide production during high-intensity exercise in horses. Am. J. Vet. Res. 61: 638-645.

12. Gollnick, P.D., and Hermansen, L. 1973. Biochemical adaptations to exercise: anaerobic metabolism. Exerc. Sport Sci. Rev. 1: 1-43.

13. Gould, D., and Udry, E. 1994. Psychological skills for enhancing performance: arousal regulation strategies. Med. Sci. Sports Exerc. 26: 478-485.

14. Hada, T., Onaka, T., Takahashi, T., Hiraga, A., and Yagi, K. 2003. Effects of novelty stress on neuroendocrine activities and running performance in thoroughbred horses. $J$. Neuroendocrinol. 15: 638-648.

15. Karlsson, J. 1971. Lactate and phosphagen concentrations in working muscle of man with special reference to oxygen deficit at the onset of work. Acta Physiol. Scand. Suppl. 358: 1-72.

16. Keenan, D.M. 1979. Changes of blood metabolites in horses after racing, with particular reference to uric acid. Aust. Vet. J. 55: 54-57.

17. Kerr, J.H. 1985. The experience of arousal: a new basis for studying arousal effects in sport. J. Sports Sci. 3: 169-179.

18. Kobayashi, M., Kuribara, K., and Amada, A. 1999. Application of $\mathrm{V}_{200}$ values for evaluation of training effects in the young thoroughbred under field conditions. Equine Vet. J. Suppl. 30: 159-162.

19. Krzywanek, H., Wittke, G., Bayer, A., and Borman, P. 1970. The heart rates of Thoroughbred horses during a race. Equine Vet. J. 2: 115-117.

20. Lehmann, M., Berg, A., Kapp, R., Wessinghage, T., and Keul, J. 1983. Correlations between laboratory testing and distance running performance in marathoners of similar performance ability. Int. J. Sports Med. 4: 226-230.

21. Lindholm, A., and Saltin, B. 1974. The physiological and biochemical response of standardbred horses to exercise of varying speed and duration. Acta Vet. Scand. 15: 310-324.

22. Lund, R.J., Guthrie, A.J., Mostert, H.J., Travers, C.W., Nurton, J.P., and Adamson, D.J. 1996. Effect of three different warm-up regimens on heat balance and oxygen consumption of thoroughbred horses. J. Appl. Physiol. 80: 21902197.

23. McCutcheon, L.J., Geor, R.J., and Hinchcliff, K.W. 1999. Effects of prior exercise on muscle metabolism during sprint exercise in horses. J. Appl. Physiol. 87: 1914-1922.

24. Medbo, J. I., and Tabata, I. 1989. Relative importance of aerobic and anaerobic energy release during short-lasting exhausting bicycle exercise. J. Appl. Physiol. 67: 1881-1886.

25. Mukai, K., Takahashi, T., Hada, T., Eto, D., Kusano, K., Yokota, S., Hiraga, A., and Ishida, N. 2003. Influence of gender and racing performance on heart rates during submaximal exercise in Thoroughbred racehorses. J. Equine Sci. 14: 93-96.

26. Persson, S. 1967. On blood volume and working capacity in horses. Studies of methodology and physiological and pathological variations. Acta Vet. Scand. Suppl. 19: 9-189.

27. Persson, S. G., and Lydin, G. 1973. Circulatory effects of splenectomy in the horse. 3. Effect on pulse-work relationship. Zentralbl. Veterinarmed. A 20: 521-530.

28. Persson, S.G.B., Essen-Gustavsson, B., Lindholm, A., McMiken, D., and Thornton, J.R. 1983. Evaluation of exercise tolerance and fitness in the performance horse. pp. 441-457. In: Equine Exercise Physiology, (Snow, D.W., Persson, S.G.B., and Rose, R.J. eds.), Granta Editions, Cambridge.

29. Poole, D.C., Barstow, T.J., Gaesser, G.A., Willis, W.T., and Whipp, B.J. 1994. $\dot{\mathrm{VO}}_{2}$ slow component: physiological and functional significance. Med. Sci. Sports Exerc. 26: 1354-1358.

30. Poole, D.C., Ward, S.A., Gardner, G.W., and Whipp, B.J. 1988. Metabolic and respiratory profile of the upper limit for prolonged exercise in man. Ergonomics 31: 1265-1279.

31. Poso, A.R. 2002. Monocarboxylate transporters and lactate metabolism in equine athletes: a review. Acta Vet. Scand. 43: 63-74.

32. Poso, A.R., Essen-Gustavsson, B., and Persson, S.G. 1993. Metabolic response to standardised exercise test in standardbred trotters with red cell hypervolaemia. Equine Vet. J. 25: 527-531.

33. Rose, R.J., and Hodgson, D.R. 1994. Hematology and Biochemistry. pp. 63-78. In: The Athletic Horse: Principles and Practice of Equine Sports Medicine, (Rose, R.J., and Hodgson, D.R. eds.), W. B. Sauders Company, Philadelphia.

34. Rose, R.J., Hodgson, D.R., Kelso, T.B., 
McCutcheon, L.J., Reid, T.A., Bayly, W.M., and Gollnick, P.D. 1988. Maximum $\mathrm{O}_{2}$ uptake, $\mathrm{O}_{2}$ debt and deficit, and muscle metabolites in Thoroughbred horses. J. Appl. Physiol. 64: 781-788.

35. Roston, W.L., Whipp, B.J., Davis, J.A., Cunningham, D.A., Effros, R.M., and Wasserman, K. 1987. Oxygen uptake kinetics and lactate concentration during exercise in humans. Am. Rev. Respir. Dis. 135: 1080-1084.

36. Sloet van Oldruitenborgh-Oosterbaan, M.M., Barneveld, A., and Schamhardt, H.C. 1995. Effects of weight and riding on workload and locomotion during treadmill exercise. Equine Vet. J. Suppl. 18: 413-417.

37. Snow, D.H. 1983. Skeletal muscle adaptations: a review. p. 160. In: Equine Exercise Physiology, (Snow, D.H., Persson, S.G.B., and Rose, R.J. eds.), Granta Editions, Cambridge.

38. Snow, D.H., and Guy, P.S. 1981. Fiber type and enzyme activities of the gluteus medius of different breeds of horse. p. 275. In: Biochemistry of Exercise, (Poortman, J., and Niert, G. eds.), University Park Press, Baltimore.

39. Snow, D.H., Ricketts, S.W., and Douglas, T.A.
1983. Post-race blood biochemistry in thoroughbreds. p. 389. In: Equine Exercise Physiology, (Snow, D.H., Persson, S.G.B., and Rose, R.J. eds.), Granta Editions, Cambridge.

40. Snow, D.H., and Vogel, C.J. 1987. pp. 100, 102, 115, 123, 156, 192, 198, 217. In: Equine Fitness. The Care and Training of the Athletic Horse, David and Charles, Inc., North Pomfret, Vermont.

41. Tyler, C.M., Hodgson, D.R., and Rose, R.J. 1996. Effect of a warm-up on energy supply during high intensity exercise in horses. Equine Vet. J. 28: 117120.

42. Yamano, S., Eto, D., Kasashima, Y., Hiraga, A., Sugiura, T., and Miyata, H. 2005. Evaluation of developmental changes in the coexpression of myosin heavy chains and metabolic properties of equine skeletal muscle fibers. Am. J. Vet. Res. 66: 401-405.

43. Yamano, S., Eto, D., Sugiura, T., Kai, M., Hiraga, A., Tokuriki, M., and Miyata, H. 2002. Effect of growth and training on muscle adaptation in Thoroughbred horses. Am. J. Vet. Res. 63: 14081412. 